\title{
ANÁLISE DOS CUSTOS DE EXTRAÇÃO E TRANSFORMAÇÃO DE MADEIRA EM COTRIGUAÇÚ-MT: ESTUDO DE CASO.
}

\author{
Odete Maria Pilati Emer ${ }^{1}$ \\ Laércio Juarez Melz
}

\begin{abstract}
RESUMO
A atividade extrativista de madeira vem sofrendo decréscimo, tanto em nível nacional, quanto em Mato Grosso, desde 2000 até 2008. O município de Cotriguaçú, também, vem reduzindo sua produção de madeira. Revela-se a importância do controle de custos para auxiliar na gestão de empresas do ramo, para continuidade do negócio. O objetivo da pesquisa foi identificar os custos mais relevantes, nas atividades de extração e transformação de madeira da Madeireira Y. A metodologia aplicada foi estudo de caso. A hipótese testada foi de que, nas atividades de extração e transformação de madeiras, os custos mais relevantes seriam os de salários e encargos sociais. Para a atividade de extração, os custos mais relevantes foram os de combustíveis e lubrificantes, utilizados nas máquinas pesadas e equipamentos. A hipótese para a atividade de extração foi, portanto, refutada. Para a atividade de transformação, contudo, foi validada a hipótese, pois, $66 \%$ dos valores gastos são destinados ao pagamento dos salários e encargos sociais.
\end{abstract}

Palavras-chaves: Indústria madeireira. Contabilidade de custos. Gestão empresarial.

\section{INTRODUÇÃO}

Aproximadamente $86 \%$ das madeireiras de Mato Grosso localizam-se no norte, noroeste e oeste do estado. Em 2000 eram aproximadamente 1749 firmas no estado. Tradicionalmente, em Mato Grosso, a atividade de extração de madeira antecede à criação de gado bovino, principalmente, no norte do estado (PIGNATIL; MACHADO, 2008).

A atividade extrativista vem sofrendo reduções nas quantidades produzidas. Enquanto no Brasil, a queda foi de 35,5\% da quantidade de metros cúbicos extraídos, entre 2000 e 2008, Mato Grosso teve queda de $43 \%$ na produção desta atividade neste mesmo período (IBGE, 2010). Aproximadamente $10 \%$ da madeira extraída no Brasil, em 2008, originou-se de Mato Grosso e 4\% das extrações do estado foram no município de Cotriguaçú (IBGE, 2010). O cenário da indústria madeireira sofreu queda na produção devido às crescentes apreensões de madeira extraída ilegalmente. O reflexo foi sentido, também, pelas empresas devidamente legalizadas.

Diante desse contexto, revela-se de grande importância a utilização de projetos de manejo para extração de madeira, como forma de amenizar os impactos causados à natureza. A utilização de projetos de manejo pressupõe consciência ambiental e atitude proativa dos

\footnotetext{
${ }^{1}$ Contadora formada pela UNEMAT - Turma fora de sede de Juina, Campus de Tangará da Serra, odete_pilati@hotmail.com

${ }^{2}$ Mestre em Engenharia de Produção (UFSCar), Professor do Departamento de Ciências da UNEMAT Campus de Tangará da Serra, laercio@unemat.br
} 
profissionais da administração. O controle efetivo das operações torna-se essencial neste contexto de escassez de matérias-primas e de novas exigências do consumidor.

A alocação dos custos de produção aos produtos, evitando sub ou supervalorização, vem desafiando gestores e pesquisadores de diversas áreas do conhecimento. A metodologia do Custeio Baseado em Atividades (ABC) veio responder aos problemas de arbitrariedade presentes na aplicação do custeio por absorção (MARTINS, 2003). A distribuição dos custos indiretos de fabricação aos produtos é o motivo pelo qual aplica-se diferentes metodologias de custeio. A existência de um custeio puramente baseado em atividades é, contudo, difícil de ser empregada.

Dada a importância da pesquisa nesta cadeia e do uso de sistemas de custeio para tomada de decisão, o objetivo proposto nesta pesquisa foi apresentar um modelo de custeio híbrido por absorção e baseado em atividades para madeireiras, mediante aplicação em caso específico. O problema apresentado foi: quais os custos mais relevantes nas atividades de extração e transformação de madeiras na madeireira Y, em Cotriguaçú-MT? A hipótese testada foi de que os custos mais relevantes da atividade são os salários e encargos dos trabalhadores, em ambas as atividades.

\section{MARCO TEÓRICO}

\subsubsection{CUSTEIO BASEADO EM ATIVIDADES (ABC)}

O Custeio Baseado em Atividades (ABC) apresenta-se como evolução do custeio por Absorção, amplamente difundido entre empresas de diversos ramos, por ser aceito para efeitos fiscais na empresa (CREPALDI, 2006). A metodologia do ABC pressupõe que os recursos empregados pela firma são consumidos nas atividades produtivas ou auxiliares da produção (MARTINS, 2003). Neves e Viceconti (2008, p. 146 e 147) esclarecem ainda que "no custeio $\mathrm{ABC}$, o objetivo é rastrear quais as atividades da empresa que estão consumindo de forma mais significativa seus recursos".

O ABC utiliza-se de direcionadores de recursos para identificar os recursos consumidos pelas atividades produtivas ou auxiliares. O objetivo identificar os custos indiretos relacionados às atividades que acontecem em cada departamento (MEGLIORINI, 2007). Para isso são identificadas, em primeiro momento, as atividades realizadas pelos departamentos e, em seguida, definidos os recursos consumidos pelas atividades. O quadro 1 mostra a estrutura do custeio ABC. 


\begin{tabular}{|l|l|l|}
\hline \multicolumn{1}{|c|}{ Departamentos } & \multicolumn{1}{|c|}{ Atividades } & \multicolumn{1}{c|}{ Direcionadores } \\
\hline Compras & $\begin{array}{l}\text { Comprar Materiais } \\
\text { Desenvolver fornecedores }\end{array}$ & $\begin{array}{l}\text { Numero de pedidos } \\
\text { Numero de fornecedores }\end{array}$ \\
\hline Almoxarifado & $\begin{array}{l}\text { Receber materiais } \\
\text { Movimentar materiais }\end{array}$ & $\begin{array}{l}\text { Numero de recebimentos } \\
\text { Tempo de preparação }\end{array}$ \\
\hline Montagem & $\begin{array}{l}\text { Preparar maquinas } \\
\text { Montar conjuntos }\end{array}$ & $\begin{array}{l}\text { Tempo de preparação } \\
\text { Tempo de montagem }\end{array}$ \\
\hline Pintura & $\begin{array}{l}\text { Preparar maquinas } \\
\text { Pintar conjuntos montados }\end{array}$ & $\begin{array}{l}\text { Tempo de preparação } \\
\text { Tempo de pintura }\end{array}$ \\
\hline
\end{tabular}

Fonte: Megliorini, (2007)

Quadro 1 Estrutura do Custeio ABC.

O sistema de custeio $\mathrm{ABC}$ procura, igualmente, amenizar as distorções provocadas pelo uso do rateio, necessários aos sistemas tratados anteriormente, principalmente no que tange ao sistema de custeio por absorção. $\mathrm{O}$ fato dos custos serem totalmente incorporados ao valor dos estoques permite que este sistema de custeio seja aplicável para fins de Imposto de Renda.

\section{METODOLOGIA}

E quanto aos objetivos, o estudo caracteriza-se descritiva e explicativa (GIL, 2002). A pesquisa utilizou-se de levantamento bibliográfico. Foi realizado estudo de caso realizado em uma Empresa de Extração e de transformação de madeira, empresa de pequeno porte, situada no município de Cotriguaçu, Estado do Mato Grosso. Os dados de produção foram levantados por pesquisa documental.

Para realizar as etapas da pesquisa, foram consultadas fontes primárias de dados, relatórios detalhados da contabilidade gerencial da empresa. As principais peças fornecidas foram: Balancete mensal, planilhas de produção, planilhas de absorção e custo e relatórios técnicos e econômicos sobre a gestão e o desempenho da empresa, com informações sobre o uso dos recursos e fatores de produção.

O espaço de análise foi delimitado, na dimensão produto: madeira. Na dimensão tempo fora utilizados os dados de agosto de 2008, mês de maior movimentação do produto. Na dimensão local, delimitou-se a Madeireira Y em Cotriguaçú-MT. O nome da madeireira 
foi ocultado a pedido dos proprietários, que gentilmente ofereceram acesso a todos os documentos necessários. Na dimensão elo da cadeia, foram analisados os elos de extração e beneficiamento de madeira (SOUZA FILHO, GUANZIROLI E BUAINAIN, 2008).

Foram realizadas entrevistas com o contador, gerente e proprietário da Empresa Madeireira. As entrevistas serviram para compreender o processo de produção e as particularidades inerentes à atividade madeireira.

\section{ANÁLISE DOS RESULTADOS}

\subsection{A EMPRESA ANALISADA}

A empresa analisada foi fundada em 1989, procurando processar matéria-prima oriunda de várias fontes. Adquiriu projetos florestais de terceiros, comprou madeira em toros de exploradores da região. Também comprou madeira serrada para processar o beneficiamento e atender seus clientes.

Ao longo do tempo, visualizando modificação radical no cenário, adquiriu áreas de florestas e implantou projetos de manejo sustentado e de exploração. Adquiriu, assim, aproximadamente 13.800 hectares de terras. Além destas, adquiriu também áreas degradas onde os Órgãos de Fiscalização do Meio Ambiente permitiam projetos de reflorestamentos. Obteve, assim, área total de, aproximadamente, 15.800 hectares, incluindo o plantio de 666.660 árvores da espécie denominada de TEKA (tectona grandis).

As atividades da indústria madeireira pesquisada são extração, transformação e beneficiamento de madeiras nobres. O mercado alvo, o internacional, é extremamente exigente. A empresa atende, também, à demanda interna. Por esse motivo houve necessidade da implantação de sistema de custeio, como suporte às suas decisões.

A partir do ano 2000, a empresa entrou no mercado externo. Em 2003, impulsionada pela desvalorização do real frente ao dólar, e com o aumento do valor histórico do metro cúbico de madeira no mercado externo, obteve resultado satisfatório. Isto motivou a Administração a mudar sua dinâmica de trabalho, com as seguintes atitudes:

- Aumentou o salário de todos os funcionários e ofereceu melhores condições de trabalho. Implantação do provento de gratificação por assiduidade e mais esmero na classificação do produto beneficiado e acabado; 
- Investiu em geração de energia própria como fator importante na redução de custos, aproveitamento do resíduo de produção e melhora no trato com as questões do meio ambiente;

- Passou a utilizar um sistema de comando direto em cada uma das Unidades, fazendo com que cada um dos responsáveis tivesse autonomia para solução de problemas, recorrendo à Administração somente em casos fora do procedimento estabelecido, o que provocou um aumento de produtividade e satisfação dos responsáveis pelas unidades ao receber maiores salários; - ainda, reduziu drasticamente a rotatividade de pessoal;

- Melhorou o sistema de secagem, com a implantação de um sistema de controle mais rígido, e investiu na qualificação dos operadores de estufa;

- Investiu em equipamentos que permitiram melhor acabamento nos produtos e maior ganho de produtividade;

- Melhorou o sistema de padronização da madeira processada para o mercado externo e melhor qualidade na embalagem;

- Passou a extrair, prioritariamente, matéria prima de suas próprias reservas, o que minimizou os custos, permitiu maior aproveitamento e conservação das reservas. A seleção das espécies botânicas consideradas ótimas, garantindo sobre tudo a preservação e a manutenção por tempo indefinido das reservas;

- Contratou elemento de venda no mercado externo que passou a atuar diretamente junto aos clientes, atendendo as exigências formuladas, observando as tendências de mercado e o direcionamento que estes clientes tomavam em relação ao mercado mundial;

- Buscou através das prerrogativas legais, o crédito presumido do IPI decorrente das operações de exportação, cujo crédito proporcionou um aumento considerável na capacidade de investimento ao economizar algo em torno de $\mathrm{R} \$ 800.000,00 \mathrm{em}$ impostos federais.

\subsection{ATIVIDADES REALIZADAS NAS UNIDADES DA EMPRESA ANALISADA}

O processo de transformação e beneficiamento de madeiras acontece em várias fases contínuas. Para seguir o processo, a empresa criou departamentos segundo a atividade 
realizada no processo produtivo. A apropriação dos custos acontece em dois estágios: primeiro a atividade e depois aos produtos.

As atividades realizadas são: extração, serragem, secagem, beneficiamento, seleção de produtos acabados, geração de energia e movimentação de carga. Os custos relacionados às atividades são descritos nas seções seguintes.

\subsubsection{UNIDADE DE EXTRAÇÃO}

Nesta Unidade que se inicia o processo de produção da serraria em análise. Inicialmente, são escolhidos os indivíduos botânicos considerados ótimos para abate, dentro da espécie solicitada pela produção e que esteja marcado como árvore permitida para o corte.

O processo constitui-se de, após a escolha, aparar a árvore dentro das normas exigidas, considerando-se altura de no máximo quarenta centímetros do solo, utilizando-se para isto moto serras de sabre longo. Depois do corte a árvore é arrastada por equipamento denominado Skeeder, que tem dispositivo próprio para suspender o topo (pé) do toro de madeira. O toro é mantido suspenso enquanto transportado, evitando assim rompimento ou rachadura danosa ao aproveitamento da madeira serrada. A madeira serrada é depositada em área denominada "praça”, daí a expressão "empraçamento". Lá recebe, imediatamente após a medição (cubagem), plaqueta de identificação para registro da produção diária.

Em seguida, utilizando pá mecânica com dispositivo para carregar madeiras em toros, a madeira é colocada em caminhões do tipo plataforma e transportada para o pátio de estocagem da Unidade de Serraria.

As variedades de maior importância na atividade são: Amapá, Angelim, Cedro, Cerejeira, Champagne, Cumaru, Cupiuba, Freijó, Cambará, Garapeira, Garrote, Guaritá, Ipê, Itaúba, Jatobá, Jequitibá, Marinheiro, Marupá, Maçaranduba, Peroba, Sucupira e Tauarí.

\subsubsection{UNIDADE DA SERRARIA}

A entrada por espécie de toros de madeira na linha de alimentação automática depende da organização e a ordenação do material a ser transformado (serrado). Isso acontece em função da necessidade de atendimento aos pedidos programados das outras unidades de processamento.

O toro de madeira é levado até o início da linha de produção por pá carregadeira sobre rodas, com dispositivo para carregar madeiras em toros. Lá, dependendo do tamanho, a 
arvore é seccionada ao meio, originando assim duas toras. Estas são movimentadas tanto pelo macaco virador de toras, como pelo guincho elétrico até que as correntes do sistema de alimentação atuem no arrasto. Ao final da linha de arrasto, o toro é virado adequadamente e preso ao sistema por grampos acionados por sistema de ar comprimido.

Certificado que o toro está devidamente fixado, mede-se a altura do toro e regula a haste horizontal da serra fita. Em seguida, aciona-se o sistema de arrefecimento por água e inicia-se o deslocamento do carro "porta toras", passando pela serra fita. Elimina-se primeiro a casca (designada costaneira) do toro, até que haja alinhamento horizontal e vertical da peça.

Aciona-se novamente o dispositivo de avanço. Determina-se a espessura do corte da peça, com uso do bitolador automático, e desloca-se o carro "porta tora" até o seccionamento total da peça. Esta é, então, retirada por dois operadores de pé de fita. A peça retirada é colocada sobre o carro troleibus e empurrada para a serra circular. Na Serra circular recebe corte para divisão, nas espessuras determinadas pela ordem de processamento. O processo continua até o corte da última peça.

Após os cortes preliminares, são selecionadas as peças. A seleção é de acordo com o comprimento, a espessura e a largura e ainda os defeitos da própria madeira. São separadas aquelas que podem ser processadas em cortes especiais, em aproveitamento específico. Os resíduos que são levados para queima na caldeira ou nas fornalhas das estufas de secagem. $\mathrm{O}$ transporte é feito em recipientes que permitem arrasto ou suspenso por pás carregadeiras. Somente o pó da madeira é transportado por correias com alcatruzes para o depósito ou para o forno de queima

Esta movimentação é informada à Secretaria Estadual do Meio Ambiente (SEMA), via Internet. Solicita-se à SEMA a transformação de toros de madeira da determinada espécie. Designa-se pelo nome popular mais aceito e pelo nome científico. O resultado da transformação em madeira serrada é registrado no sistema da SEMA com o mesmo nome popular e científico que deu origem.

\subsubsection{UNIDADE DE SECAGEM}

O processo de secagem requer conhecimentos empíricos, científicos, tecnologia avançada, e investimento. É o processo mais complexo e que muitas vezes acarreta prejuízos imensuráveis à firma.

Inicialmente a madeira, normalmente da mesma espécie e ou da mesma família, é colocada uma sobre a outra, horizontalmente. Entre cada peça é colocado um varão de 
madeira dura, criando espaço que irá permitir a circulação de ar e de vapor quente entre elas. Após esta operação, chamada de "gradear", é colocada ao relento quando considerada madeira dura, recebe tratamento contra fungos e aguarda na fila de espera para entrar na estufa. Após alguns dias, a madeira é levada para a estufa, e as "grades" são colocadas umas sobre as outras, utilizando-se empilhadeiras hidráulicas. Empilha-se até que se tenha atingido a altura máxima dentro de cada estufa. Esta altura varia de acordo com a capacidade de cada estufa.

Depois de carregadas, são fechados hermeticamente todos os orifícios que possam permitir vazamento de vapor e calor. São fechadas as portas, ficando abertos no rés do chão. Rés são canais, que permitem escoamento da água retirada da madeira no processo de secagem. Depois do fechamento é colocado fogo nas fornalhas das estufas. São abertas as válvulas de vapor para preenchimento dos radiadores de circulação, nas estufas movidas a vapor. A partir deste momento, os funcionários responsáveis pela unidade de secagem entram em escala de revezamento. Em nenhum momento as estufas devem ficar sem monitoramento. As fornalhas devem ser alimentadas corretamente dia e noite. Estufas automatizadas requerem menor dedicação.

A secagem termina entre oito e doze dias. É iniciado, então, o processo de descarregar a estufa. Em seguida, envia-se a madeira para a Unidade de Beneficiamento.

\subsubsection{UNIDADE DE BENEFICIAMENTO}

A Unidade de Beneficiamento recebe a madeira, após o processo de secagem, e seleciona as peças que apresentam defeitos. Elimina os defeitos com apara em serra circular ou destopadoras elétricas. Em alguns casos, há exclusão total da peça danificada. Em seguida procede da seguinte forma:

1) Madeira destinada ao mercado interno é colocada em fardos para contagem, cubagem e determinação da quantidade de peças em relação ao percentual de peças curtas abaixo do padrão geralmente aceito. Este trabalho constitui na seleção visual, com duas pessoas selecionando e anotando no romaneio de embarque, e duas montando o fardo;

2) Ainda para o mercado interno, quando destinada à indústria de móveis, pode sofrer cortes em tamanhos especiais, ser aplainada em duas faces, que é denominada de 
SK2S (S2S) (seca e aplainada em duas faces). Após é embalada em fardos fechados com fita de aço. O trabalho é executado da mesma forma descrita anteriormente;

3) Também para o mercado interno, pode ser aparada em vários comprimentos e larguras, mas com mesma espessura. Os comprimentos obedecem aos percentuais em relação ao numero total de peças do pedido. As peças devem ser aplainadas em quatro faces. Esse processo gera peças denominadas de SK4S (S4S) (seca e aplainada em quatro faces). Em seguida, é embalada em fardos com fechamento com fita de aço e plástico insufilme.

4) Para o mercado externo, a madeira é aparada em vários comprimentos e largura, mas a mesma espessura. Os comprimentos obedecem a percentuais em relação ao número total de peças do pedido. As peças devem ser aplainadas em quatro faces, SK4S (S4S) (seca e aplainada em quatro faces). Recebe, ainda, tratamento contra fungos (fumigação), sendo embalada em fardos com fechamento com fita de aço e plástico insufilme. O tratamento contra fungos acontece devido ao longo tempo de armazenamento em containers durante o transporte.

$\mathrm{Na}$ fase de beneficiamento, os processos desenvolvem-se ou complementam-se da seguinte maneira:

1) Ao aparar as peças de madeira, que anteriormente sofreram processo de secagem, é utilizada uma mesa com esteira rolante, totalmente automatizada. Existem, inclusive, sensores que detectam umidade fora do padrão aceito, tanto no mercado interno, como externo. Estes sensores, ao verificar umidade acima da permitida, emitem um impulso que através de um braço varredor expurga da esteira a peça rejeitada;

2) Este mesmo processo determina e executa o corte no tamanho mínimo, médio, intermediário e máximo do lote de peças que são preparados;

3) Aplainar as peças significa passar as peças por equipamento denominado de plaina. Este equipamento possui facas (montadas em sistema de rebolo) extremamente afiadas, que operam em velocidades altíssimas. Quanto maior o numero de eixos e capacidade de variar a velocidade, mais sofisticado é o trabalho efetuado. Este equipamento é operado por pessoal especializado, produz nível altíssimo de ruído. Existe, ainda, neste equipamento, sistema de exaustão de pó e de serragem extremamente potente; 
A movimentação de madeira na etapa de secagem é informada à SEMA, via Internet.

\subsubsection{UNIDADE DE PRODUTOS ACABADOS}

A Unidade de Produtos Acabados recebe a madeira após o processo de beneficiamento. Nesta unidade são selecionadas as peças, de acordo com a bitola. Em seguida passa aos seguintes procedimentos:

1) Para atender ao mercado interno, podem ser processadas peças terminadas como barras de cama, portais e alisares. Ainda podem ser processadas em réguas para piso, lambris com encaixe macho e fêmea.

2) Ainda para o mercado interno, aproveitando o acabamento (S2S) (seca e aplainada em duas faces), sofre modificações de acordo com pedidos especiais de indústria. Podem, também, ser fresadas longitudinalmente, biseladas, ou acabamento especial para deck's;

3) Para o mercado externo, sofre padronização final, corte para montagem de pisos, e em alguns casos até semi-acabamento com lixa. O processo de acabamento, normalmente, é feito na madeira classificada como (S4S) (seca e aplainada em quatro faces), inclusive deck.

Deve-se observar que toda madeira destinada ao mercado externo deve ter Certificado de Origem, tratamento fitossanitário, tratamento contra fungos (fumigação), e embalada em fardos com fechamento com fita de aço e plástico insufilme e acabamento esmerado.

\subsubsection{UNIDADE GERADORA DE ENERGIA}

A Unidade Geradora é de apoio, pois, gera energia para todo o processo produtivo, além da administração. O objetivo desta unidade é gerar energia e vapor, utilizando os resíduos de madeira do processo industrial, através de caldeiras e geradores. É utilizada, neste processo, a caldeira com sistema de fornalha que, com queima de resíduos, movimenta o gerador elétrico. Tem, como auxiliares, o tanque de água (espelho de água) a estrutura monumental para instalação da caldeira, linha de transmissão de energia elétrica.

Para operar o sistema, é necessário engenheiro mecânico especializado e autorizado para revisão e emissão de laudo de vistoria. São necessários, também, operadores de caldeira, 
devidamente profissionalizados e autorizados legalmente para operar este equipamento. Os trabalhadores estão sujeitos a leis específicas do Ministério do Trabalho. São obrigados ao cumprimento de escala de revezamento e técnico em eletricidade.

\subsubsection{UNIDADE DE MOVIMENTAÇÃO DE CARGA}

O trabalho, nesta unidade, consiste em atender o pátio de operações da serraria e das demais unidades do processo industrial. Entre suas atribuições, estão:

1) Retirar, do pátio de estoque, os toros de madeira que devem ser transformados. Colocálos na linha de alimentação da serraria de acordo com a solicitação de produção;

2) Remover para o pátio a madeira serrada que será selecionada e colocada em pallets para secagem;

3) Remover os pallets, depois de montados e preparados para a fila de espera das estufas;

4) Descarregar a estufa, removendo o material após o processo de secagem, para a unidade de beneficiamento;

5) Recarregar a estufa, organizando o empilhamento;

6) Remover pallets da unidade de beneficiamento para a unidade de produtos acabados;

7) Remover detritos da serraria para a fornalha da caldeira e das estufas não automatizadas;

8) Remover pallets dentro da unidade de produtos acabados para embalagem final, quando for material para exportação e carregar os caminhões de longo percurso;

Para estas operações são utilizadas pás carregadeiras com garfo específico para toros de madeira e para pallets, empilhadeiras hidráulicas pequeno e médio porte, pá mecânica e caminhões. Como equipamento auxiliar é utilizado guincho elétrico, moto serra, bobinador para plástico insufilme, máquina para selo mecânico de fardo e etc.

\subsection{CUSTOS DE EXTRAÇÃO E TRANSFORMAÇÃO}

\subsubsection{CUSTOS NA UNIDADE DE EXTRAÇÃO}

Nesta fase são utilizados equipamentos como tratores de esteira de grande porte, moto niveladoras, pás carregadeiras, caminhões com caçamba basculante, caminhão plataforma para transporte de toros de madeira, skeeder para arrasto de toras até o local denominado de 
"praça", moto serras, grupo gerador de energia de pequeno porte. Para dar suporte a estas operações são necessários: depósito de grande porte combustível, ferramentas para mecânica, conjunto de solda elétrica.

O pessoal necessário a esta fase é composto de funcionários especializados em operação de máquinas pesadas, motoristas e operadores de moto serra, cozinheiro, pessoal especializado em identificação de espécies botânicas, (identificador florestal) e trabalhadores comuns para apoio de operações. Os salários e os respectivos encargos são elaborados por Unidade, permitindo a apropriação específica.

Com o advento da implantação do sistema de compras pela Administração da empresa, todos os gastos são apropriados através de requisição emitida pelo responsável da Unidade de Extração ao almoxarifado central. O combustível é requisitado diretamente do depósito de campo, como forma de racionalizar o procedimento. Ao final de cada período, de um mês, é possível determinar o custo da atividade em relação à sua produtividade.

Nesta unidade, existe uma pequena inversão de valores gastos em relação a outras unidades. Observou-se que combustíveis e lubrificantes têm o percentual mais elevado. Isso acontece porque nesta atividade estão os equipamentos mais pesados do parque de máquinas, portanto, maior consumo de combustíveis (Tabela 1).

Antes do início da extração, são construídas as pontes, a abertura das estradas, o pátio de estocagem (empraçamento). Se anteriormente já foram feitos estes serviços, no ano seguinte é necessário recuperá-los totalmente, pois, a incidência das chuvas provoca bastante estrago.

Nesta operação, normalmente, são utilizados dois tratores de grande porte, motoniveladora, pás carregadeiras, caminhões do tipo caçamba, skeeder para arrastar a madeira para as pontes.

$\mathrm{Na}$ seqüência das operações, acontece a extração propriamente dita. Nesta se utilizam equipamentos como skeeder, tratores, pás carregadeiras com o sistema para toras (estes garfos são escamoteáveis), caminhões do tipo plataforma para transporte de toras, moto serras e grupo gerador.

É importante observar que, a somatória dos custos de máquinas e de veículos se aproxima da metade dos custos com combustíveis e lubrificantes. Estes itens são registrados em separado, para que se possa exercer gerenciamento constante sobre eles. É de extrema importância o acompanhamento, principalmente sobre os de máquinas pesadas. Isto permite definir condições de operação, qualidade do operador, determinante na troca do equipamento e etc. 
Tabela 1. Custos incorridos na atividade de extração, Agosto/2008, em R\$ e \% .

\begin{tabular}{c|c|c}
\hline Item & Custo & Participação (\%) \\
\hline Acampamento Provisório & $10.921,83$ & 12,39 \\
Combustível e Lubrificantes & $37.220,46$ & 42,22 \\
Salários + encargos & $20.467,46$ & 23,22 \\
Manutenção de Galpões/Instalações & 87,96 & 0,10 \\
Manutenção de Máquinas Leves & 574,36 & 0,65 \\
Manutenção de Máq. Pesadas & $7.190,02$ & 8,16 \\
Manutenção de Veículos & $8.498,65$ & 9,64 \\
Manutenção de Máquina Operatriz & $2.630,08$ & 2,98 \\
Material de Consumo & 126,11 & 0,14 \\
Uniformes/Aventais/EPI & 356,55 & 0,40 \\
Utensílios de Pouca Duração & 87,55 & 0,10 \\
\hline Total & $\mathbf{8 8 . 1 6 1 , 0 3}$ & $\mathbf{1 0 0 , 0 0}$ \\
\hline
\end{tabular}

O gasto com pessoal é um dos menores, comparado com outras unidades. Mesmo exigindo maiores salários para operadores de máquinas pesadas, motoristas, mecânicos e identificador botânico, a equipe é menor. Um identificador botânico é suficiente para uma equipe de operadores de moto serra, por maior que seja a equipe. Um mecânico atende a várias máquinas, partindo do principio que o uso da manutenção preventiva é fácil e exige menos tempo. Poucos operadores de moto serras extraem muitas árvores no dia, pois o caminho de fuga é pequeno, quando se usa skeeder para retirar a tora.

Os gastos com acampamentos são resultantes da permanência do pessoal no campo de operações durante toda a semana, e ai estão incluídos os gastos com alimentação, camas de campanha, instalação provisória e etc.

\subsubsection{CUSTOS NA SERRARIA}

Para execução desta transformação é utilizado macaco hidráulico para movimentação na linha de alimentação, linha de alimentação hidráulica. Utiliza-se, também, carro porta toras, bitoladores automáticos, serras fita de grande porte. O carro "troleibuss" é usado para movimentação de pranchas pesadas. Multi-serras para desdobramento e aproveitamento de madeiras. Serras circulares de grande porte para desdobrar e aparar madeira. 
Como equipamentos auxiliares, são utilizadas: unidade afiação e ferramentaria para manutenção de cabeçotes, afiação de serras fitas, arqueamento e emendas de serras.

Os salários e os respectivos encargos sociais são elaborados por Unidade, permitindo a apropriação direta.

Os custos indiretos da atividade da serraria são: consumo de combustível, manutenção de maquinas leves (moto-serras outros), manutenção de serraria (composto por todo o conjunto de maquina que efetiva o processo de serrar), manutenção de Instalações, material de consumo (correntões, pregos, lonas, etc.), uniformes, aventais e equipamento de proteção individual EPI e outros.

Todos os gastos desta unidade são apropriados através de requisição emitida pelo responsável da Unidade ao almoxarifado central, como forma de racionalizar o procedimento. Ao final de cada período, é possível determinar o custo da atividade em relação à sua produtividade.

\subsubsection{CUSTOS NA UNIDADE DE SECAGEM}

Na unidade de secagem, são gastos: peças utilizadas na reparação de empilhadeiras usadas para carga, descarga e empilhamento dos fardos de madeiras preparadas para secagem; Rolamentos, hélices, condensadores, radiadores para manutenção de estufas automatizadas, alumínio e zinco em folhas para reparação das unidades; Ferro redondo, vergalhão, eletrodo para solda elétrica e fornalhas e queimadores para manutenção de estufas não automatizadas.

Para execução da secagem, em estufas não automatizadas, são utilizados resíduos de madeira. Quando necessários, são adquiridos de terceiros como complemento. Os salários e encargos sociais são elaborados por Unidade, permitindo a apropriação direta.

Também aqui os gastos são apropriados através de requisição emitida pelo responsável da Unidade ao almoxarifado central. Ao final de cada período, é possível determinar o custo da atividade em relação à sua produtividade.

\subsubsection{CUSTOS NA UNIDADE DE BENEFICIAMENTO}

Nesta unidade, os gastos são referentes a recuperação de cabeçotes, aquisição de cabeçotes, recuperação de fresas, fresas, automatiza dores, rebolos, rolamentos e hélices para exaustores, correias transportadores. Os materiais de consumo, como tintas marcadoras, 
fungicidas, fumigadores, pistolas de pintura também são apropriados a esta unidade. Os salários e encargos sociais são elaborados por Unidade, permitindo a apropriação direta.

Os gastos são apropriados através de requisição emitida pelo responsável da Unidade ao almoxarifado central. Ao final de cada mês, determina-se o custo da atividade em relação à sua produtividade.

\subsubsection{CUSTOS NA UNIDADE DE PRODUTOS ACABADOS}

Os gastos nesta unidade são similares à de Beneficiamento. São eles: recuperação de cabeçotes, cabeçotes, recuperação de fresas, fresas, automatizadores, rebolos, rolamentos e hélices para exaustores, correias transportadores. Consumo de materiais como: tintas marcadoras, fungicidas, fumigadores, pistolas de pintura e, materiais de embalagem plásticos do tipo insufilme, fitas de aço, cantoneiras para embalagem. Os salários também e os encargos sociais são apropriados na respectiva unidade.

Os custos são apropriados através de requisição emitida pelo responsável da Unidade ao almoxarifado central. Ao final de cada mês, determina-se o custo da atividade em relação à sua produtividade.

\subsubsection{CUSTOS NA UNIDADE GERADORA DE ENERGIA}

$\mathrm{Na}$ unidade geradora de energia, os custos ocorrem com uso de rolamentos especiais para mancais do sistema do cavalo a vapor, correias de transmissão e luvas elásticas, material de solda, material de isolamento do tipo asbestos e fibra de vidro.

Os combustíveis e lubrificantes em geradores de reserva, quando na manutenção e reparação da unidade geradora. Chaves triângulos de alta voltagem, transformadores, óleos para transformadores, fios de alta tensão, disjuntores unipolares, bipolares e tripolares. Elementos químicos para limpeza de tubulação aérea das caldeiras e eliminadores de cálcio e magnésio das tubulações. Bombas d água do sistema de arrefecimento, canos galvanizados, luvas e demais acessórios do sistema de encanamento de água, equipamento de EPI.

Os salários e encargos sociais são apropriados diretamente na unidade. Os custos são apropriados por requisição emitida ao almoxarifado central. Ao final de cada período, é determinando o custo da atividade em relação à sua produtividade. 


\subsubsection{CUSTOS NA UNIDADE MOVIMENTAÇÃO DE CARGA}

Na unidade de movimentação de cargas, são consumidas peças para veículos pesados do tipo caminhão plataforma, caminhão de longo percurso, caminhão caçamba para remoção de detrito para fornalhas de estufas e de caldeiras. Utilizam-se, também, peças para máquinas e equipamentos do tipo pás mecânicas e pás carregadeiras, empilhadeiras e correias transportadoras. Também os salários são apropriados diretamente na unidade.

Os gastos são apropriados por meio de requisição emitida ao almoxarifado central. Desta forma, ao final de cada mês, é possível conhecer o custo da atividade em relação à sua produtividade.

\subsubsection{CUSTOS DE TRANSFORMAÇÃO}

Na transformação, a mão-de-obra apresenta-se como o item e maior relevância nos custos (Tabela 2). Isso acontece porque exige-se grande qualificação profissional, com vistas a maior qualidade do produto final.

$\mathrm{Na}$ opinião do empresário, o plano de incentivo adotado no início da retomada administrativa para o crescimento teve êxito exatamente nesta atitude, e hoje é tratado cada vez mais com critério.

Tabela 2. Custos de transformação por atividade, agosto/2008, em R\$.

\begin{tabular}{|c|c|c|c|c|c|c|c|c|}
\hline Custo & Serraria & $\begin{array}{c}\text { Secage } \\
\text { m }\end{array}$ & $\begin{array}{c}\text { Beneficiament } \\
\text { o }\end{array}$ & $\begin{array}{l}\text { Produto } \\
\text { acabado }\end{array}$ & $\begin{array}{c}\text { Geradora } \\
\text { de } \\
\text { energia }\end{array}$ & $\begin{array}{l}\text { Mov. } \\
\text { Carga }\end{array}$ & $\begin{array}{l}\text { Custo } \\
\text { Total }\end{array}$ & $(\%)$ \\
\hline Combustível e Lubrif. & $\begin{array}{l}3.860,00 \\
33.635,4\end{array}$ & - & - & $\begin{array}{c}- \\
14.329,0\end{array}$ & $10.999,99$ & $\begin{array}{c}11.368,8 \\
5\end{array}$ & $26.228,84$ & 20,13 \\
\hline Salarios + encargos & 3 & $6.709,26$ & $18.597,10$ & 4 & $10.211,32$ & $3.192,92$ & $86.675,07$ & 66,53 \\
\hline Manut.Caldeira & - & - & - & & $5.301,45$ & & $5.301,45$ & 4,07 \\
\hline Manut. De Estufas & - & 497,89 & - & & & & 497,89 & 0,38 \\
\hline Manut.Galpões/Instala & 635,00 & 231,25 & 28,33 & & 655,33 & & $1.549,91$ & 1,19 \\
\hline Manut.Máquinas Leve & 519,14 & - & - & & & & 519,14 & 0,40 \\
\hline Manut.Máq. Pesadas & - & - & - & & & 183,25 & 183,25 & 0,14 \\
\hline Manut.Veiculos & - & - & - & & & 336,23 & 336,23 & 0,26 \\
\hline Manut.Maq.Operatriz & - & 580,94 & - & & & $1.165,58$ & $1.746,52$ & 1,34 \\
\hline Manut.Serraria & $2.919,23$ & - & - & & & & $2.919,23$ & 2,24 \\
\hline Material de Embalagem & - & - & 425,33 & $1.901,88$ & & & $2.327,21$ & 1,79 \\
\hline Material de Consumo & 133,00 & 29,68 & 69,45 & 121,03 & 93,87 & 114,01 & 561,04 & 0,43 \\
\hline
\end{tabular}




\begin{tabular}{|c|c|c|c|c|c|c|c|c|}
\hline $\begin{array}{c}\text { Uniformes/Avent/EPI } \\
\text { Utens. de Pouca } \\
\text { Duração }\end{array}$ & $\begin{array}{l}148,33 \\
187,05\end{array}$ & $\begin{array}{l}298,66 \\
22,09\end{array}$ & 198,22 & 103,54 & $\begin{array}{l}263,72 \\
42,10\end{array}$ & 93,42 & $\begin{array}{c}1.105,89 \\
325,43\end{array}$ & $\begin{array}{l}0,85 \\
0,25\end{array}$ \\
\hline Total & $\begin{array}{c}42.037,1 \\
8\end{array}$ & $8.369,77$ & $19.392,62$ & $\begin{array}{c}16.455,4 \\
9\end{array}$ & $27.567,78$ & $\begin{array}{c}16.454,2 \\
6\end{array}$ & $\begin{array}{c}130.277,1 \\
0\end{array}$ & $\begin{array}{c}100,0 \\
0\end{array}$ \\
\hline
\end{tabular}

Percebeu-se que, além dos salários e encargos, os combustíveis e lubrificantes destacam-se, principalmente, porque a geração de energia da caldeira ainda é insuficiente. Exigindo auxílio por geradores movidos a motor diesel. Na movimentação de carga o grande consumo destes recursos é comportamento normal, decorrente do número de equipamentos que concorrem para este setor.

Ressalte-se que, na empresa analisada, não foram contabilizados os custos de depreciação de máquinas e equipamentos de qualquer espécie. Após estudo e levantamento do comportamento do mercado em relação a equipamentos usados, chegou-se à conclusão de que, um equipamento pesado pode ser usado pelo menos durante cinco anos se for praticada manutenção preventiva e operado com as respectivas recomendações técnicas, este pode manter preço muitas vezes superior ao valor de aquisição.

Deste levantamento, concluiu-se que a depreciação seria inútil, e estaria, além disso, compensada pelos gastos de manutenção e conservação. $O$ valor original e real dos equipamentos, devido à manutenção, representaria a realidade do Ativo Imobilizado. Além de, lógico, oferecer maior confiabilidade nas análise efetuadas pelos fornecedores e comitês de crédito das instituições financeiras. Fato comprovado pela aprovação do comitê de credito do Banco do Brasil S.A., na pretensão de Projeto do FCO.

\subsection{ANÁLISE DOS CUSTOS DE EXTRAÇÃO E PRODUÇÃO}

\subsubsection{ANÁLISE DOS CUSTOS DE EXTRAÇÃO}

A partir da mensuração dos gastos por atividade, estes são levados para a composição do custo produto. Equivale dizer que, na unidade de extração, é a formação do preço de custo da matéria-prima. Neste estudo, tomou-se como base analítica um mês de alta produtividade, agosto de 2008 (Tabela 3).

Tabela 3. Custos de extração, agosto/2008, em R\$. 


\begin{tabular}{c|c|c|c|c|c|c}
\hline Nomenclatura & $\begin{array}{c}\text { Quantidade } \\
\text { Extraída }(\mathbf{m 3})\end{array}$ & $\begin{array}{c}\text { Custo } \\
\text { Arvore em Pé }\end{array}$ & $\begin{array}{c}\text { Custo } \\
\text { Extração }\end{array}$ & $\begin{array}{c}\text { Custo } \\
\text { Total }\end{array}$ & $\mathbf{( \% )}$ & Custo/m3 \\
\hline Angelim & 130,00 & $11.700,00$ & $3.655,45$ & $15.355,45$ & 5,04 & 118,12 \\
Angelim Amargo & 213,51 & $20.781,12$ & $6.003,72$ & $26.784,84$ & 8,80 & 125,45 \\
Cedro Rosa & 65,74 & $9.541,73$ & $1.848,45$ & $11.390,18$ & 3,74 & 173,27 \\
Cumaru & 5,20 & 599,21 & 146,13 & 745,34 & 0,24 & 143,42 \\
Cupiaba & 192,54 & $18.892,42$ & $5.414,12$ & $24.306,54$ & 7,98 & 126,24 \\
Garapeira & 72,17 & $7.593,52$ & $2.029,28$ & $9.622,80$ & 3,16 & 133,34 \\
Garrote & 173,14 & $16.913,85$ & $4.868,44$ & $21.782,29$ & 7,16 & 125,81 \\
Guarita & 92,57 & $8.807,30$ & $2.603,02$ & $11.410,32$ & 3,75 & 123,26 \\
Ipê & 271,79 & $38.050,88$ & $7.642,48$ & $45.693,36$ & 15,01 & 168,12 \\
Itauba & 192,53 & $18.290,64$ & $5.413,81$ & $23.704,45$ & 7,79 & 123,12 \\
Jatoba & 69,64 & $6.646,82$ & $1.958,31$ & $8.605,13$ & 2,83 & 123,56 \\
Marupá & 108,88 & $13.091,73$ & $3.061,58$ & $16.153,31$ & 5,31 & 148,36 \\
Maçaradumba & 157,68 & $15.889,72$ & $4.433,87$ & $20.323,59$ & 6,68 & 128,89 \\
Peroba Mica & 30,00 & $3.052,80$ & 843,57 & $3.896,37$ & 1,28 & 129,88 \\
Tauari & 408,12 & $53.162,23$ & $11.475,98$ & $64.638,21$ & 21,23 & 158,38 \\
\hline Totais & $\mathbf{2 . 1 8 3 , 5 2}$ & $\mathbf{2 4 3 . 0 1 3 , 9 7}$ & $\mathbf{6 1 . 3 9 8 , 2 1}$ & $\mathbf{3 0 4 . 4 1 2 , 1 8}$ & $\mathbf{1 0 0 , 0 0}$ & $\mathbf{1 3 9 , 4 1}$ \\
\hline
\end{tabular}

$\mathrm{Na}$ formação do custo da matéria-prima foi considerado o valor da árvore em pé. Este valor é apurado pelo levantamento feito na elaboração do Projeto de Manejo Sustentado.

Ressalte-se que, durante a extração, nem sempre é recomendável extrair madeira de mesma espécie ou de mesmo valor de mercado. A explicação para tal recomendação deve-se ao fato de que, o custo por metro cúbico de extração é o mesmo para qualquer espécie. Se extraída espécie de baixo valor de venda, será registrado prejuízo na operação ao se apurar resultados. Ao contrário, lucro muito alto acontece nas operações de espécies com alto valor de mercado. Portanto, recomenda-se planejar a extração, estabelecendo relação entre atender as solicitações de mercado já efetivadas, a tendência do mercado e a exportação, equalizando assim o resultado.

\subsubsection{ANALISE DOS CUSTOS DE TRANSFORMAÇÃO}

A partir da mensuração dos gastos por atividade, estes são levados para a composição do custo produto. Nas unidades de transformação, os custos correspondem ao custo do produto acabado, (madeira serrada, madeira beneficiada e especificidades inerentes a várias classificações segundo exigências de mercado). Neste estudo, tomou-se como base analítica um mês de alta produtividade (Tabela 4). 
Tabela 4. Distribuição dos custos aos produtos, agosto/2008, em R\$.

\begin{tabular}{|c|c|c|c|c|c|c|c|c|c|}
\hline Produto & $\begin{array}{l}\text { MP } \\
(\mathbf{m 3})\end{array}$ & $\begin{array}{l}\text { Custo } \\
\text { Médio } \\
\mathbf{R} \$ \mathbf{m} 3\end{array}$ & $\begin{array}{c}\text { Total } \\
\text { MP } \\
(\mathbf{R} \$)\end{array}$ & $\begin{array}{c}\text { Gastos } \\
\text { Gerais } \\
(\mathbf{R} \$)\end{array}$ & $\%$ & $\begin{array}{c}\text { Custo } \\
\text { Total } \\
(\mathbf{R} \$)\end{array}$ & $\begin{array}{c}\text { Produto } \\
\text { Elaborado } \\
(\mathrm{m} 3)\end{array}$ & $\begin{array}{c}\text { Custo } \\
\text { Unitário } \\
(\mathbf{R} \$)\end{array}$ & $\begin{array}{c}\text { Sobras } \\
(\mathbf{m} 3)\end{array}$ \\
\hline Angelim & 13,19 & 118,12 & $1.558,58$ & $93.257,87$ & 0,64 & $2.159,99$ & 7,26 & 297,63 & 5,94 \\
\hline Angelim Amargo & 329,05 & 125,45 & $41.278,86$ & $93.257,87$ & 16,08 & $56.276,42$ & 180,98 & 310,96 & 148,07 \\
\hline Angelim Pedra & 178,40 & 118,12 & $21.072,84$ & $93.257,87$ & 8,72 & $29.204,21$ & 98,12 & 297,63 & 80,28 \\
\hline Cerejeira & 354,82 & 119,33 & $42.340,75$ & $93.257,87$ & 17,34 & $58.513,08$ & 195,15 & 299,83 & 159,67 \\
\hline Cumaru & 319,37 & 143,42 & $45.804,68$ & $93.257,87$ & 15,61 & $60.361,40$ & 175,66 & 343,63 & 143,72 \\
\hline Garapeira & 35,79 & 133,34 & $4.771,79$ & $93.257,87$ & 1,75 & $6.402,90$ & 19,68 & 325,31 & 16,10 \\
\hline Garrote & 87,55 & 125,81 & $11.014,43$ & $93.257,87$ & 4,28 & $15.004,77$ & 48,15 & 311,62 & 39,40 \\
\hline Jatoba & 351,30 & 123,59 & $43.417,28$ & $93.257,87$ & 17,17 & $59.429,18$ & 193,22 & 307,58 & 158,09 \\
\hline Maçaranduba & 361,92 & 128,89 & $46.648,26$ & $93.257,87$ & 17,69 & $63.144,30$ & 199,06 & 317,22 & 162,87 \\
\hline Tauari & 14,68 & 158,39 & $2.325,17$ & $93.257,87$ & 0,72 & $2.994,26$ & 8,07 & 370,85 & 6,61 \\
\hline Totais & $2.046,08$ & & $260.232,63$ & & 100,00 & $353.490,50$ & $1.125,34$ & & 920,73 \\
\hline
\end{tabular}

Tabela 5. Rateio dos custos das unidades aos produtos, agosto/2008, em R\$.

\begin{tabular}{|c|c|c|c|c|c|c|c|c|c|}
\hline Produto & $\begin{array}{c}\text { Produto } \\
\text { Elaborado } \\
(\mathbf{m 3})\end{array}$ & $\begin{array}{c}\text { Part. } \\
\text { Prod. } \\
(\%)\end{array}$ & $\begin{array}{c}\text { Rateio } \\
\text { Custos } \\
(\mathbf{R} \$)\end{array}$ & $\begin{array}{c}\text { Custos } \\
\text { Serraria } \\
(\mathbf{R} \$)\end{array}$ & $\begin{array}{c}\text { Custos } \\
\text { Secagem } \\
(\mathbf{R} \$)\end{array}$ & $\begin{array}{c}\text { Custos } \\
\text { Benef. } \\
(\mathbf{R} \$)\end{array}$ & $\begin{array}{c}\text { Custos } \\
\text { Prod. Acab. } \\
\text { (R\$) }\end{array}$ & $\begin{array}{c}\text { Custos } \\
\text { Geradora } \\
(\mathbf{R} \$)\end{array}$ & $\begin{array}{c}\text { Custos } \\
\text { Mov. Cargas } \\
\text { (R\$) }\end{array}$ \\
\hline Angelim & 7,26 & 0,64 & 601,41 & 239,27 & 47,97 & 65,18 & 92,41 & 129,01 & 27,58 \\
\hline Angelim Amargo & 180,98 & 16,08 & $14.997,56$ & $5.966,76$ & $1.196,23$ & $1.625,45$ & $2.304,37$ & $3.217,06$ & 687,70 \\
\hline Angelim Pedra & 98,12 & 8,72 & $8.131,36$ & $3.235,05$ & 648,57 & 881,28 & $1.249,38$ & $1.744,22$ & 372,86 \\
\hline Cerejeira & 195,15 & 17,34 & $16.172,33$ & $6.434,14$ & $1.289,93$ & $1.752,77$ & $2.484,87$ & $3.469,05$ & 741,57 \\
\hline Cumaru & 175,66 & 15,61 & $14.556,72$ & $5.791,37$ & $1.161,07$ & $1.577,67$ & $2.236,64$ & $3.122,50$ & 667,48 \\
\hline Garapeira & 19,68 & 1,75 & $1.631,11$ & 648,94 & 130,10 & 176,78 & 250,62 & 349,88 & 74,79 \\
\hline Garrote & 48,15 & 4,28 & $3.990,34$ & $1.587,55$ & 318,28 & 432,48 & 613,11 & 855,95 & 182,97 \\
\hline Jatoba & 193,22 & 17,17 & $16.011,90$ & $6.370,31$ & $1.277,14$ & $1.735,38$ & $2.460,22$ & $3.434,64$ & 734,21 \\
\hline Maçaranduba & 199,06 & 17,69 & $16.496,04$ & $6.562,92$ & $1.315,75$ & $1.787,85$ & $2.534,61$ & $3.538,49$ & 756,41 \\
\hline Tauari & 8,07 & 0,72 & 669,10 & 266,20 & 53,37 & 72,52 & 102,81 & 143,53 & 30,68 \\
\hline Totais & $1.125,34$ & 100,00 & $93.257,87$ & $37.102,50$ & $7.438,40$ & $10.107,36$ & 14.329,04 & \begin{tabular}{|l|}
$20.004,32$ \\
\end{tabular} & $4.276,25$ \\
\hline
\end{tabular}

A tabela 4 traz o valor dos Gastos Gerais que são agregados à matéria-prima. Estes valores constam na tabela 3 , realizando o rateio proporcionalmente à quantidade transformada. Definindo assim o custo final por metro cúbico de madeira serrada e das sobras e ou resíduos que são utilizados para a geração de energia, fator determinante de continuidade de produção. Estes resíduos são contabilizados primeiramente em quebra técnica, e, se aproveitados na venda como aproveitamento, registra-se a recuperação de despesas. 
A tabela 5 mostra os valores rateados de cada unidade produtiva para o produto final elaborado. O rateio foi feito com base na produtividade, conforme foi descrito nas subsecções da seção 4.3 .

\section{CONSIDERAÇÕES FINAIS}

Em contexto de decréscimo da produção de madeira, tanto no Brasil, como em Mato Grosso. A função da gestão torna-se crucial para o desenvolvimento da atividade. O conhecimento dos custos de produção oferece subsídios para a correta tomada de decisão. Nem mesmo as pequenas empresas devem subestimar o uso da informação gerencial.

O problema apresentado foi: quais os custos mais relevantes nas atividades de extração e transformação de madeiras na madeireira Y, em Cotriguaçú-MT? A hipótese testada foi de que, nas atividades de extração e transformação de madeiras, os custos mais relevantes seriam os de salários e encargos sociais. Para a atividade de extração, os custos mais relevantes foram os de combustíveis e lubrificantes, utilizados nas máquinas pesadas e equipamentos. A hipótese para a atividade de extração foi, portanto, refutada. Para a atividade de transformação, contudo, foi validada a hipótese, pois, $66 \%$ dos valores gastos são destinados ao pagamento dos salários e encargos sociais.

Sugere-se que a metodologia seja aplicada em outras empresas do mesmo porte em municípios diferentes, pois, a pesquisa limita-se ao estudo de um único caso, com dados de curto período de tempo e local específico.

\section{REFERÊNCIAS}

CREPALDI, Silvio Aparecido. Contabilidade Gerencial: teoria e prática. $3^{\circ}$ ed. São Paulo: Atlas, 2006.

GIL, Antonio Carlos. Como Elaborar Projetos de Pesquisa. 4.ed. São Paulo: Atlas, 2002. IBGE, Instituto Brasileiro de Geografia e Estatística. Produção da Extração Vegetal e da Silvicultura. Disponível em:

$<\mathrm{http} / / / \mathrm{www} \cdot$ sidra.ibge.gov.br/bda/acervo/acervo2 $\cdot \mathrm{asp}$ ? $=\mathrm{v} \& \mathrm{p}=\mathrm{VS} \& \mathrm{z}=\mathrm{t} \& \mathrm{o}=18>$. Acesso em: 30 mar. 2010.

MARTINS, Eliseu. Contabilidade de Custos. 9.ed. São Paulo: Atlas, 2006.

MEGLIORINI, Evandir. Custos. São Paulo: Makron Books, 2001.OLIVEIRA, Antônio

Benedito. Métodos e Técnicas de Pesquisa em Contabilidade. São Paulo: Saraiva, 2003. 
NEVES, Silvério; VICECONI, Paulo E.V. Contabilidade de Custos: um enfoque direto e objetivo. 8 ed. São Paulo: Frase Editora, 2008.

PIGNATIL, W.A.; MACHADO, J. M. Riscos e agravos à saúde e à vida dos trabalhadores das indústrias madeireiras de Mato Grosso. in Ciências saúde coletiva. Vol.10 n.4. Rio de Janeiro: Oct./Dec. 2005. Disponível em

<http://www.scielosp.org/scielo.php?pid=S141381232005000400019\&script=sci_artte> . Acesso em: 12/08/2008.

SOUZA FILHO, Hildo Meirelles; GUANZIROLI, Carlos Enrique; BUAINAIN, Antonio Marcio. Metodologia para estudo das relações de mercado em sistemas agroindustriais. Brasilia: IICA, 2008. 